\title{
(Re)Examining the Feminist Interview: Rapport, Gender "Matching," and Emotional Labour
}

\author{
Rachel Thwaites* \\ School of Social and Political Sciences, University of Lincoln, Lincolnshire, United Kingdom
}

OPEN ACCESS

Edited by:

Masoumeh Velayati,

Al-Maktoum College

of Higher Education,

United Kingdom

Reviewed by:

Hannah Fitsch,

Technische Universität

Berlin, Germany

Cornelia Schadler,

University of Vienna, Austria

${ }^{*}$ Correspondence:

Rachel Thwaites

rthwaites@lincoln.ac.uk

Specialty section:

This article was submitted to

Gender, Sex and

Sexuality Studies,

a section of the journal

Frontiers in Sociology

Received: 13 June 2017

Accepted: 26 October 2017

Published: 10 November 2017

Citation:

Thwaites R (2017) (Re)Examining the Feminist Interview: Rapport, Gender

"Matching," and Emotional Labour.

Front. Sociol. 2:18.

doi: 10.3389/fsoc.2017.00018
Rapport is usually considered key to any interview situation: building the right kind of rapport can be the difference between success and failure in obtaining the required data. In feminist research, rapport is intended to be of a particular kind: created through mutual sharing, minimal power hierarchies, and a feeling of genuine trust between interviewer and interviewee (Oakley, 1981). There is a tension here of which feminist researchers and scholars should remain critical, as the idea of good feminist rapport can clash with the necessity of "getting the data." Building rapport can entail minimising strongly held viewpoints, working hard on one's emotions to ensure they do not reveal true thoughts, or suggesting an attitude of trust and mutual understanding that may feel disingenuous. If rapport is often a performance by the researcher, then this can clash with the intended open and honest feminist approach. In some cases, then, building rapport may pose a challenge to genuinely following a feminist approach to the research interview. In this paper, I wish to explore this tension in more detail in the context of the one-off interview and to what extent it can be resolved.

Keywords: emotional labour, feminist methods, gender matching, interviewing, rapport, research methods

\section{INTRODUCTION}

This article aims to extend the debate around feminist scholarship and methods by examining the one-off feminist interview and the complex part that rapport plays within it. I contend that rapport always has the potential to be exploitative and, hence, conflict with the widely accepted feminist research aim of equitable power sharing in interviews, that should mean participants are cared for and empowered. I am focussing my attention on interviews with "everyday" participants, rather than "expert interviewees" (there may well be different issues concerning approach and rapport with experts). As I will outline in more detail below, rapport in feminist research has been undertheorised (Dunscombe and Jessop, 2002 are an exception), with limited engagement with wider literature on the complexities of rapport and the ethical dilemmas it raises. Rapport-frequently thought of in terms of "gender matched" interviews between women (Oakley, 1981)-has been glossed over as more naturally occurring and not in need of critical engagement in the face of other pressing issues around feminist methods. Yet, in so doing feminists can miss the real potential for exploitation in their research and move away from the intellectual and political goal of knowledge created in an equitable space.

Feminist scholarship on methods and methodology has been extensive, critical, and transformatory (Oakley, 1981; Harding, 1986), not only for feminist researchers but for the wider social sciences. Feminist scholars have been willing to focus in on the research process and critique taken-for-granted 
assumptions about research and established methods for doing research. Ann Oakley's discussion of the interview (1981), as a highly significant method for feminist research, was crucial to this debate and sparked off major change in the social sciences, as well as further debate around methods and feminist research; it continues to be highly significant as a starting point today (see, for example, Dunscombe and Jessop, 2002) and will, therefore, be taken as an important starting point for this article also. One aspect of the interview that is significant to both the data collected, and the relationship between researcher and participant, is rapport. Rapport comes into every research situation, but in the intimate interview it is most clearly involved and important to the outcome of the discussion and the ultimate data collected/ created. Rapport is complex, however, and the discussion of it in feminist research must be a nuanced and critical one.

The perspective I am arguing for in this article comes from an understanding of the feminist interview, and indeed most feminist research, as holding on to specific values and aims, as set out by Oakley in her seminal article (1981). These are the empowerment of participants in research; hearing often silenced voices; minimising the power hierarchy between researcher and participant; encouraging the participant to lead research; equal sharing of opinions, thoughts, and ideas to minimise the exploitation of the participant (by taking their data, while giving nothing in return); and honest, open discussion of the messy, subjective nature of research when writing it up (Oakley, 1981). These are important and laudable aims, and I agree that feminist researchers should remain committed to trying to achieve them in research wherever possible. However, in this article I want to argue for the need to remain critical about our research processes, with particular reference to rapport. Rapport has received little specific critical attention from feminist scholars since Oakley: Dunscombe and Jessop (2002) are notable exceptions to this and their argument has been highly influential for this article, though I wish to extend their discussion of how to think of and actualise (or not) rapport when identifying as a feminist researcher who accepts the general principles of this kind of research as outlined above. Rapport is entered into research in terms of how to build it and ensure it is maintained, but less so in terms of the politics of building it itself.

When building rapport, there may well be an element of acting, of not presenting a "true" self to the participant, or indeed of having to hide one's own thoughts and feelings so as not to offend the participant and risk losing their cooperation. Feminist scholars have discussed the best methods for collecting data, the issue of "matching" interviewer and interviewee in research, the emotional labour involved in dealing with complex and difficult narratives, and the ethics of feminist research (Maynard, 1994). However, when taking rapport as the central focus, discussion of these issues gains a new perspective. Feminist scholars should remain alert to when rapport does come easily, when it has to be created with more work, whether it should be created, and/ or whether more may be gained by risking the participant's cooperation to have a more honest discussion with them. For example, when examining experience of health and illness with a group of older people who express racist views, should one try to move the discussion on without challenging them or actively focus on what has been said and why it is offensive to the researcher? Should a person in an interview setting expressing views that are highly traditional about the place of women in society be challenged and held to account, or allowed to express their honest views without comment from the researcher? And how should the researcher feel about either course of action and the potential impact on the research findings? This article will explore this issue by analysing the one-off interview in feminist research and the place of rapport within it, examining the current literature on rapport and the significant issues of emotional labour and "matching" in interview situations; then, placing rapport within an ethical framework, it will suggest that rapport needs to be examined critically by feminists to see what part it plays in their process and the final dataset they produce with their participants. Finally, it will question whether rapport is always necessary and whether feminist scholars need to be more honest about the reality of the research process when they do build rapport.

\section{RAPPORT IN SOCIAL SCIENCE RESEARCH}

Rapport in qualitative, social science research has been explored from a variety of disciplinary perspectives, with sustained focus in anthropology and sociology in particular (Abell et al., 2006; Ryan, 2006; Pitts and Miller-Day, 2007; Mitchell and Irvine, 2008; Bott, 2010; Boccagni, 2011; Tonnaer, 2012; Brayda and Boyce, 2014; Soyer, 2014; Berger, 2015; Petkov and Kaoullas, 2016). The anthropological work takes a special interest in rapport in ethnography and the complexities of building trust and recognition in long-term research situations. Pitts and Miller-Day (2007), p. 178, discussing the available literature on rapport, argue that developing this trusting relationship is key to achieving validity in qualitative research, but is nevertheless difficult to create and secure; they argue that reciprocity is highly important in establishing this trust, as well as "reception formations" such as gender, race and ethnicity, class, age, and so on, which have an impact on how and to what extent the participant will receive the researcher (Pitts and Miller-Day, 2007: pp. 180-181). Brayda and Boyce (2014) note that even when one holds "insider" status-shared cultural background, for example-rapport does not necessarily emerge. It is the intersection of these "reception formations" that is crucial. In this instance, gender and cultural background together could create instant trust (Brayda and Boyce, 2014: p. 326), but, in some cases, this shared cultural background opened up the possibility of a deviant insider status, suggesting political motives for carrying out the research and deep mistrust (Brayda and Boyce, 2014: p. 327). There is a need for constant reflection on the way in which interviewers are positioned by interviewees and the impact this can have on rapport, as well as the ways in which researchers position their participants.

As Bott (2010), pp. 159-160, argues (see also Stanley and Wise, 1993) that feminist and queer methodologies have had a significant impact on much social science research around reflexivity, disclosure, and power in research. The research process is highly complex and requires continual reflection from the researcher about how particular interpretations of data are arrived at and 
what this will mean for the state of knowledge in that particular field going forward (Bott, 2010: p. 160). The researcher must locate him or herself within their research, carefully considering their influence on the findings, and their own construction of self within the research to minimise the power they hold over the telling of the life story of the interviewee (Haraway, 1991; Ramazanoglu, 2002; Skeggs, 2002; Bott, 2010). Rapport is highly significant to how one and one's participants become located within the research and how one interprets the data: as one begins to "identify/disidentify, like/dislike, familiarize/etherized" (Bott, 2010: p. 160). This is an issue for all social science researchers, but for feminist researchers it can threaten the ethics of their research process, which is intended to minimise power, empower silenced voices, and treat all participants with the same respect and interest. Equally though, it shows the importance for researchers of not subsuming their full self to the performance of rapport to "get the data" - particularly if a participant makes comments that are sexist, racist, and so on (Bott, 2010: p. 167). Researcher and participant subjectivities are of critical salience to rapport, to findings, and to interpretation of those findings.

However, as Abell et al. (2006) argue, subjectivities within research are complex and difference and distance can be created even when trying to disclose, bring closer, and share power. Therefore, whether to "match" interviewer and interviewee using specific categories-ethnicity, gender, class, age, for example-is an ongoing discussion in qualitative research and one of significance to rapport. In feminist research, the issue of "gender matching"-due to feminist researchers often prioritising gender as a research focus and lens-has come under particular scrutiny. This in part because gender matching was set up in earlier feminist writings on research as important for genuine rapport, trust, and reciprocity. This will be discussed in more detail below, but Abell and colleagues' work (Abell et al., 2006) (see also Berger, 2015) is a useful reminder that "matching" and identification between researchers and researched do not always yield the expected or desired results. Furthermore, as Mitchell and Irvine (2008) argue, disclosure may not always be what an interviewee wants from an interview and it can close off rapport rather than build it.

This literature recognises both the complexity and the significance of disclosure and personal presentation to securing good relationships and good data. It also recognises the amount of work that can go into creating these relationships (Ryan, 2006; Pitts and Miller-Day, 2007) and that this work may not always be pleasant-the display of friendship can be entirely a performance (Ryan, 2006: pp. 157-158). Though, as Ryan (2006) argues, this kind of "faking" of friendship is something most researchers wish to avoid-in part because they simply do not feel they can or wish to spend further time with the participants they dislike-it is a recognised part of social science research.

In ethnographic studies, there may be time to really get to know participants; in the one-off interview rapport must be established quickly. This creates its own possibilities and tensions: rapport can be harder to create in such short meetings, but it can also be more easily "faked" for the good of the research. The one-off interview is, therefore, potentially higher-stakes when it comes to rapport creation-there is a serious risk of failure to create rapport and loss of a significant chunk of data-but it also offers the chance to perform rapport in the most intense fashion, with limited risk of being revealed if not being honest about one's opinions, thoughts, or feelings. Dunscombe and Jessop (2002) have called this "doing rapport," reflecting the potential to manipulate others in the performance of rapport to "get" the data [see also Birch and Miller (2000) on the therapeutic possibilities of interviews, which may be uncomfortable for the interviewer], as well as the fact this doing of rapport is often commodified as necessary for part of paid work (particularly for those on shortterm contracts who have not set the boundaries of the research themselves). It is this potential that sits uneasily with feminist values when interviewing, as outlined by Oakley.

\section{ANN OAKLEY, THE FEMINIST INTERVIEW, AND RAPPORT}

Ann Oakley, in her 1981 chapter in Doing Feminist Research, set up the interview as the exemplar feminist method. She worked to reframe the interview as it had been set up in Sociology hitherto and to place it centrally within feminist research, scholarship, and practice. Her discussion centred on the interview as, at the time, taught to students and budding researchers as if it followed an "objective" and natural scientific process, in which data were elicited from participants who told the truth of their lives. Oakley (1981) was critical of this narrative around interviewing and the expectation that interviewers would remain at a remove from their participants; she argued that this was unrealistic and indeed, poor practice when looking to get the best data while also protecting one's participant from feelings of exploitation. She also suggested that this was, in particular, not the best way to obtain data from women (Oakley, 1981: p. 41).

This argument had a significant impact on feminist scholarship, and many embraced Oakley's thoughts on how the interview should be run and conceptualised, even if, as Oakley has stated, this was not her intention at the time (Oakley, 2015: p. 199). These arguments have since spread beyond feminist work in the social sciences and have been embraced by many researchers, who feel that the interview is anything but "objective." The issue of objectivity will be discussed in more detail below, but here I wish to focus on the underlying assumptions upon which Oakley's assessment of the interview situation is based, to set up some of the reflections on this method that I will extrapolate below. Oakley's arguments remain important and compelling, but there are aspects of them that feminist scholars should continue to reflect upon and be critical of as they work through the research process. ${ }^{1}$

First, the suggestion that the interview process should be changed from a "scientific" process to a more realistic assessment of it as subjective and involved is crucial to a full understanding of feminist methods. However, this opens up an issue of which feminist researchers need to be careful: the issue of rapport. When encouraged to build rapport with one's participants, to gather data and make them feel at ease, while also sharing stories about

${ }^{1}$ Oakley has herself commented on the reaction to this 1981 article and amended and qualified some of her argument (Oakley, 2015). 
one's own life and thoughts, this creates a sense of togetherness and closeness in that research setting. Oakley argued that this was something that women do together and that real friendships can be built (1981: 46). Though this may well have been the case for Oakley, and for other feminist researchers (see, for example, Skeggs, 1997), this cannot always be how research works due to the very nature of different projects, timescales, and objectives. Pushing this kind of intimate rapport building as the central aim of feminist work brings up a number of concerns.

Rapport is set up in Oakley's argument as something natural, coming from the shared trust built between women, and as something good, honest, and open. The fact it is also a means to rich data is less significant in her argument, but is an important secondary concern. However, rapport is not a necessarily natural result of any two people having a discussion about a research topic. As in the rest of life, rapport can exist easily between people or it can be very difficult to achieve; it may have to be created rather than flow in any "natural" sense. The focus on this as bound to occur between women essentialises gender in an unhelpful way, as I expand upon below, in line with other feminist critics. However, with the focus on building and maintaining rapport in feminist interviews-while also holding to high expectations of power sharing, sharing life experiences, thoughts and opinions, and being honest about the messiness of the research process-feminist interviewing can become contradictory and opaque. Rapport building complicates honesty and sharing, and in fact, more pragmatic decisions have to be made in research situations when there is pressure to "get the data" (Dunscombe and Jessop, 2002) or indeed to protect oneself from powerful participants.

In many ways, empirical research is a performance and the identity one projects as a researcher in this situation is created through that particular situation and time. Though many-one would hope most-researchers will be genuinely interested in the stories of participants and will be happy to present themselves as outgoing and affable during the research situation, it is important to reflect on the work that goes into this presentation, most especially the emotional labour that can be involved, and in what ways this work connects to the other aspects of power sharing, gender identity, and honest, open discussion of the researcher's views and opinions. As Birch et al. (2012), pp. 5-6, argue, feminist research is about context rather than "abstract rules and principles" and there is an ongoing need to be reflexive. Birch et al. (2012), p. 6, are concerned that there is a growing perception of the "ideal" researcher as caring - and, therefore, committed to all the indepth emotional work that goes along with this; they are also concerned that "feminist perspectives" may now be "synonymous with ethical ways of working," which they argue can be "misleading and offer more than it can deliver." They call for contextual and critical practice and this is an argument I wish to follow on from this article, exploring some of the complexities in holding onto this idea of feminist research as caring and ethical, while critically looking at the realities of rapport building and the potential for "faking friendship" (Dunscombe and Jessop, 2002). Rapport has an impact on what we hear from interviewees, how we interpret their stories, and therefore the knowledge we produce and use in the world; it is highly important to consider how it works and its relation to a wider feminist approach. I will start by examining the emotional labour inherent in qualitative research, a key means of performing rapport.

\section{EMOTIONAL LABOUR}

Increasingly, the emotional work involved in qualitative research is being foregrounded by researchers and openly discussed; yet it remains a fairly new area of academic interest with the academic setting focussed on "rational" research outputs (Dickson-Swift et al., 2007). The complexity of emotion and emotional labour that is a part of the research process is, therefore, under-discussed. Hochschild's study (Hochschild, 1983, 2003a) on the emotion work flight attendants engage in while dealing with customers and in managing their own emotions has been highly influential in studies on emotion in a multitude of different occupations and situations (see, for example, Korczynski, 2003; Yang and Chang, 2008; Thwaites, 2017). Her ideas about "framing rules" for situations and the work that is done on oneself to comply with these rules is particularly pertinent here.

Hochschild argues that there are "framing rules" which guide emotion and action within particular situations (Hochschild, 2003b: p. 99). These framing rules about emotional response are what people judge their own reaction against; if it is found wanting they may work on their emotions until they fit the situation in a socially acceptable way. There are essentially rules around how to feel. Furthermore, people will manage their emotions using either surface or deep acting (Hochschild, 2003a: pp. 37-42): surface acting allows one to look to others as if one feels a particular way, while deep acting is such controlled and in-depth emotion management that the feeling desired comes to genuinely be felt. All of these ideas can be applied to the researcher in an interview situation, but surface acting is especially important for this discussion when considering rapport and the feminist stance towards sharing and power between interviewer and interviewee.

The framing rule for a feminist interview is one of equitable and honest sharing; rules of feeling, therefore, dictate genuine interest, compassion, and a desire to share openly. In reality though these three may or may not be present in the interview or may be present to greater or lesser degrees. However, the researcher may really feel though, s/he is compelled to act out these feeling rules in terms of words and body language. Genuine interest in the topic and compassion for others are rarely difficult for interviewers who desire to speak with other people about a new area of research, but open sharing presents difficulties. This is the point at which surface acting becomes crucial to the interviewer and where issues around guilt and exploitation really arise.

When surface acting the interviewer may not agree with a participant, but will control their emotional expression on the outside to ensure this is not conveyed to the interviewee. This can be done with a desire to safeguard the research project and get at the "real" views of the participant; however, it means full and honest sharing has been side-lined. Surface acting also controls the amount a researcher may have to share with a participant by indicating that they have no experience of what is being discussed. This is not inherently incorrect practice but to purposively withhold information from an interviewee under 
any of these circumstances through careful, exhausting, and strategic emotional labour appears to go against a number of feminist principles of interviewing. Rapport between interviewer and interviewee is, therefore, not honest or real in any sense; instead an idea of "objectivity" - in not influencing the researched in any way-raises its head. Rapport can be used to simply try not to influence responses and make the interview appear like a conversation between friends; this actually creates a form of "objectivity" in the research situation and attempts to deny the constructed nature of the research process, an idea feminists have been keen to argue against and one which sits uneasily with attempts to maintain power balance. The exploitative nature of this faked rapport is clear and can put the power balance firmly back in favour of the researcher.

This emotional labour is, however, not without its consequences for the researcher as s/he is left feeling guilty about their honesty as a feminist researcher and whether they are living up to the standards of an ideal interview (Dunscombe and Jessop, 2002: pp. 114-115, 117). Perhaps the kind of equal and cosy sharing in interviewing that has been hailed as the ideal in feminist research is only an ideal. However, if this is the case the reality needs to be more sincerely discussed by feminist researchers; though it is important to have an ideal to work towards it is as important to discuss what actually happens in feminist research situations and to prepare novice researchers in particular for the fact that the ideal cannot always be realised. This honesty about the research process remains a crucial part of what makes feminist research "feminist."

It is perhaps worth being more critical of the idea of "genuine" emotional experience in light of the work in the Sociology of Emotions on this very issue. Hochschild's argument was that we become alienated from these real and genuine emotions through our emotional labour when we surface act and that deep actingthough we do come to feel the intended emotions-is a process of work that changes our original and more genuine feelings to fit the feeling rule (Hochschild, 2003a: p. 56). My argument pertains closely to this in saying that the interview is, to some extent, a performance, and that feelings are not always genuinely shown to participants. As with any work situation there is a professional status that must be maintained and emotional labour is a central part of this. It is, therefore, not to lie or be in some hurtful way disingenuous with participants, but it is not always helpful or right to fully show one's feelings and emotions; participants would not always want or expect this, sometimes this would not be safe for the interviewer, or may simply not be something in which the interviewer wishes to engage (Green et al., 1993). As the wider literature also make clear, there is every possibility than in trying to share and disclose personal thoughts, ideas, and experiences with the participants, the researcher can simply push them further away, suggest that the participant's opinion is less important than their own, or position themselves as knowing more than participants (Abell et al., 2006).

There are two points that spring from this discussion: first, the suggestion that there are genuine emotions that we feel, which needs some further unpacking. In suggesting that people work on their emotions to change them I do not mean to suggest that there are more "natural" emotions than others. All emotions are socially constructed and regulated (Hochschild, 2003a,b; Ahmed, 2010) and, therefore, that nothing springs from any space "before" the social. This does not mean that our initial feeling cannot be changed or that it might not fit with the feeling rule of the situation without still being a socially bound emotion. By knowing it is somehow incorrect or needs worked on, we reiterate these feeling rules on a daily basis and prove how social they are and how socially competent we are as agents in the world.

Second, "proper" expression of emotions goes unquestioned as part of the work of a professional; not doing this work or improperly displaying one's emotions can be taken as a sign of lack of professionalism and even be worthy of complaint. One's professional training may work on strategies for controlling the emotions, usually implicitly; for example, nursing staff are encouraged to minimise their disgust for patients through various means, such as using humour, distance, or by heightening their feelings of concern, and sympathy (Mann, 2005). With such a strong, even if implicit, connection between professional behaviour and controlled emotion, the suggestion that researchers should always be open about how they feel seems contradictory and may be seen as inappropriate or unwelcome by participants. Of course, feminist researchers have not advocated unthinking sharing or emotional displays, and there has been previous literature critical of any naive ideas of the progress of interviews (see, for example, Green et al., 1993); however, it is worth getting to grips with rapport and professionalism in more detail so that feminists can continue the work of being honest about the research process, the messiness of it, and the inequalities that can lie at its heart.

In Evans' work on professionalism, she has pointed out that there are numerous and contested definitions of what this actually means (Evans, 2010: p. 22). She describes numerous possible definitions that have been suggested (Evans, 2010: pp. 22-24), including a sense of quality in the work done, an attitude towards work, the values one attaches to work, and a more top-down, management idea of what the job "should" be. Professionalism is very much a normative idea of what a person should act like, think like, "be," at work (Evans, 2010: p. 25). In the British context, an idea of "the professional" is bound up with a classed work ethic, a part of the (British) professionalising middle classes in the nineteenth century separating themselves from both upper and lower classes (Gunn, 2005: p. 53). This period of professionalising, creating, and dividing disciplines and specialisms was also a period of more fully delineating class boundaries. Emotions and the work done on them are an important part of class identity, as Lawler, for example, argues (Lawler, 2005; see also Tyler, 2008). The middle-class home is also argued to be the basis of teaching children emotional control as part of civilising them for wider society (particularly the role of women); learning to be polite, controlled, and law-abiding (Gunn, 2005: pp. 55-56). This control of the emotional self feeds into the idea of the professional, neatly linking middle-class values and work. To not share too much or lose control is, therefore, a sign of the (classed) competent and worthy professional.

Oakley was one of the first feminist researchers to rally against this sanitised version of the researcher, often equated with a masculine way of doing research (Oakley, 1981; see also Oakley, 2015: p. 196), alongside its classed implications. Yet, in calling 
for honest sharing, working with women to share viewpoints and ideas, there has been an assumption that this is always harmoniously possible and will not interfere with the research. But research is not always this straightforward and there are many points at which researchers must ask themselves whether genuine sharing is possible or necessary, worth risking the co-operation of the participants over, or whether genuine sharing might lead to a much more significant conversation. Strong emotional labour, in the form of surface acting, can save the researcher from burning out or even losing her research participant. This means though that honest sharing would have to be left at the door of the interview room. I would argue that feminists need to take on subjects and populations that may well be very difficult in terms of gender and equality to try to get at some new solutions in a world of "alternative facts" and silos of understanding. Rapport built through surface acting can ensure that this occurs, to some extent, but can be a barrier to following a feminist methodology of honesty and openness, leaving researchers with the ethical conundrum that they have given their participants the wrong impression about their own viewpoints and opinions.

Dunscombe and Jessop (2002) argue clearly about the complexity of the ethical issues raised by rapport and the problems that can arise from sharing, adopting an open and affable attitude, and indeed over-sharing as the interviewer and inviting, however implicitly, the suggestion that the relationship may continue after the research is over. However, they also argue that professionalisation can equal commercialisation or commodification of feeling (Dunscombe and Jessop, 2002: p. 109) and that this very process means one sees manipulation of one's own or others' feelings as part of the job (Dunscombe and Jessop, 2002: pp. 111-112). In this case, one can become estranged from the complex ethical issues that arise from rapport building and see only the need to get the job done, most especially, they argue, when the researcher is not themselves responsible for the overall project (Dunscombe and Jessop, 2002: p. 115). Rapport can be both necessary and a danger, confounding one's ability to be honest, while covering over a multitude of ethical decisions with the façade of friendship and joviality. This façade of friendship can be increased by attempting to "match" interviewer and interviewee in terms of their background or demographic categories. As the above literature discussion should make clear, this cannot be attempted naively as even shared characteristics can be reframed to create distance. Nevertheless, with Oakley's work encouraging research "by, for, and about" women the issue of gender matching continues to raise its head for feminist researchers.

\section{GENDER MATCHING}

There has been much nuanced discussion in feminist research literature about the issue of "matching" interviewer and interviewee (see, for example, Phoenix, 1994), and Oakley herself has since nuanced her 1981 arguments (Oakley, 2015: pp. 197-198). This is a very important discussion as it raises several questions about the relationship between participant and researcher: whether people do speak more openly to certain people than others and whether this means people who are similar or different in terms of demographics. This of course then opens up a debate around which demographics are most important and if one trumps another. These questions suggest a potential to get better data from participants when they feel more comfortable with their interviewer and therefore are more likely to speak openly only with that person. Assumptions based on certain "matched" identity criteria may make for more open dialogue, more in-depth discussion, and therefore a more significant set of data for analysis.

However, "matching" has its negative sides too, as has been discussed, in part, above. A "matched" interviewer and interviewee actually has the potential to close off certain discussion because of the assumption that there are shared viewpoints and understandings of the world (Phoenix, 1994: pp. 66-67). Without a level of dis-ease created by lack of matching a participant may not give a full account of their understanding of the world based on the assumption that explanations and definitions are not required because the interviewer already understands and experiences the world in the same way as they themselves do. Interviewers may also play up to this potential as a means of growing and shaping rapport for the success of the interview more widely, inadvertently losing useful data in the process. The opposite is also risky: by asking for clarification or demanding more in-depth description from interviewees, they can confuse and frustrate their participant by raising the suggestion that they do not come from or share the same world view, closing down further dialogue. Therefore, "matching" creates tricky dynamics that are highly fragile.

The other concern around "matching" is that feminist research can actually essentialise based on particular identity characteristics, such as gender, ethnicity, or class (for example, Phoenix, 1994: p. 50). The suggestion that people may require a similar person to themselves to talk to raises the possibility that gender or ethnicity are inherent characteristics, innately providing a particular view of the world. This is a troublesome suggestion for feminists who do not see these characteristics as essential, but as constructed, changeable, and contingent on context. Of course, there has been much feminist debate around standpoint and what this means for one's view of the world and it can be argued that socialisation does provide a similar perspective on the world, albeit one that is not "natural." Black feminist perspectives, in particular, have made significant contributions here.

Collins' work on black feminist epistemologies is a useful point of discussion in terms of feminist interviewing and "matching" (Collins, 2009). Collins argues persuasively about the significance of one's standpoint to one's view of the world and her work, along with many other black feminists, has had a major influence on wider feminist scholarship. Collins (2009), p. 270, argues that one's background, experiences, and social positioning have total impacts on how one views and interprets the world. This perspective contributes to individuals' understandings of what is, but also what can be, true. The dominant group, therefore, has a monopoly on interpreting the world and deciding what knowledge is true, credible, and worthy (Collins, 2009: p. 271). Different viewpoints are required to challenge this monopoly and to bring in the undervalued but highly relevant knowledge of minority and oppressed groups. Collins' argument could be used to back up a more general feminist suggestion that women 
should be interviewed by women, as this will ensure that a collective understanding of the world is brought to the interview, minority views will be heard, and real sharing can occur from a place of shared assumptions about the world one lives in. ${ }^{2}$

This is a significant and important argument that remains useful, but, as Phoenix (1994), p. 50, argues, does not change the complexity of gender matching (or other matching) in interviewing. Reducing social relationships to one characteristic is reductionist and impossible. Patricia Hill Collins' work on intersectionality makes this very clear: identities are forged through the meeting of different social positionings to make complex individuals who have privilege in some parts of their lives and disadvantage in others, giving them their own unique perspective but one that is shaped by wider social processes and power dynamics (Collins and Bilge, 2016). In terms of rapport then, gender matching does not guarantee a successful interview or data that will in some sense be more honest that it would be otherwise. The situation is far more complex than this. Therefore, any reductionist ideas that "woman to woman" interviews are always the best form of feminist research method can hide the multitude of other important factors that come into play when interacting with another person in any situation, but most especially in the interview setting, and feminists must continue to critically reflect on this fact in their research.

Without doing this critical work, we run the risk of actually essentialising research methods themselves, with the interview as somehow always the best method for eliciting data from women, and other methods, such as surveys, as inherently masculine and, therefore, outside the feminist research toolkit. This, as Kelly et al. (1994), p. 46, have noted, is not helpful to feminist research in the long-run. It also risks creating-or perhaps reifying-a gendered hierarchy of methods, in which "feminised" methods are taken less seriously that their more "masculine" counterparts. Though the highly problematic connection between "feminised" and "less credible" is not one I wish to condone, it is also not helpful to cut ourselves off, as feminist researchers, from ways of knowing the world because of essentialising tendencies towards both methods and participants. Instead we should be asking what methods are right for our research questions and be open to all kinds of data. Methods and the data they produce are not inherently anything-feminine or masculine, feminist or otherwise-and can be used in different ways for different ends. Though feminists may not wish to force women into particular tick-boxes, forcing them to define their world in certain ways, they do not have to use surveys in such a restrictive sense; quantitative data may be highly useful in making political statements about women's lives and the need for equality. Interviews also have, as has been argued here, the potential for exploitation, even though they remain highly significant in getting at personal stories, reflections, and opinions. The research method itself is not more or less feminist; it is what the researcher chooses to do with it that counts.

\section{DISCUSSION: FEMINIST METHODS; FEMINIST ETHICS}

The question of how to use methods in "a feminist way" is obviously complex and very much a case of "easier said than done." Feminist researchers have led the way in thinking through the dynamics of research and the importance of this critical reflection (see, for example, Kelly et al., 1994; Maynard, 1994). This reflection on the significance of rapport in particular is intended to be a part of this continuing conversation. If we take the potential for exploitation in rapport building in the interview situation seriously, then we have to question the possibility for genuine power sharing and to what extent equality between participant and researcher is ever truly achieved at any stage in the research. This is not to say that participants are never in control of the research situation or that they are not at times perfectly able to become the powerful agent in that dynamic (Green et al., 1993); to suggest otherwise would be to ignore their agency also. However, truthful and honest interviews may well be impossible when one is also cognisant of the fact one must "get the data." Interviews are not straightforward and comfortable spaces of dialogue between women, as has been argued above, though rapport may be designed to make them look as though they are. Therefore, a robust understanding of feminist ethics in research is required and openness about what we actually do in research also: a very fine and very difficult balancing act of trying to achieve our research aims while doing feminist work.

I certainly do not wish to argue for an end to the aim of power sharing in research. This is an important and laudable feminist aim, which is something to strive for, and therefore not something to be abandoned. However, along with Green et al. (1993), I would argue that it is something that cannot always be achieved and is actually sometimes impossible or unhelpful: particularly when participants are highly powerful in the interview situation anyway or when the researcher may actually need and wish to establish power in difficult research situations. As Hammersley (2014), p. 535, argues, we can become too preoccupied with certain ethical issues over others. The more "naturally occurring" the situation the more, in fact, the experience can be exploitative; the more participants are aware of their involvement in a research process the less likely it is that their autonomy will be negatively affected.

Feminist research has been critical of the idea of "objectivity" in any straightforward sense (Harding, 1986). Attempts to share power, share self, and enter our subjective selves into the research process honestly have been part of this critical stance. However, the tension between this work and rapport-building pulls us back towards a less open and honest idea of "objectivity" where we ignore the complex work we are doing to maintain the relationship between ourselves and our participants. This work brings back the veneer of neutrality and value-free judgement, pulls us back from genuine sharing, and opens up our research to

${ }^{3}$ Hammersley is not arguing for the autonomy of the individual as coming above all else in ethics-quite the contrary-but does make the point that the so-called "naturally occurring" situations have their own ethical pitfalls.
${ }^{2}$ I am not suggesting that Patricia Hill Collins argued this herself, but that the standpoint argument adds significant weight to the theory that matching in interviews is best practice. 
accusations of seeing gender matched interviewing as essentialist and cosy work, where women freely share with one another because (and only because) they are women. This veneer may well keep an interview on-track, but it also returns feminist research to the traditional canon of "objective" research. Meaning, research that makes itself look uncomplicated and value-free, ignoring the messiness and realities of the actual research situation, the viewpoint of the researcher and its impact on the work in the research situation itself.

There are perhaps two ways forward from this point and neither of them are easy, but I would hope they are worth considering nevertheless. The first option is to acknowledge our lack of honesty in the research situation and discuss the emotional labour, rapport-building techniques, suppression of viewpoints, and so on that we used to ensure the interview continued. This would allow us to be honest about our approach and remain critical about taking this option. Rapport is significant to ensuring you get the data and it is not always easy to maintain; interviews (and other forms of research) are also not always easy to perform, and it is worth feminists reflecting on the realities of this in their work, their strategies, and their potential impact on the participant and on the findings.

The second option is to enter the interview as a space of dialogue and discussion and reduce the focus on easy rapport. This may well be something to discuss in advance with the interviewee and to set up the discussion as one of open dialogue. Of course, if rapport does come easily then there is continued reflective work to be done on shared assumptions and viewpoints and what this might mean for the resulting data. If viewpoints are at odds and rapport is hard to build then accepting this and openly discussing points of tension and dissonance could be a part of the critical work of reframing "objectivity" in research. In this way, we can be honest with our participants and stay true to our feminist objectives, though we may lose rapport through lack of emotional labour. The second option is highly risky, as the whole enterprise could end the relationship with the research participant, depending on the nature of the research topic and discussion. The interview as a method may well have to be reconsidered for topics too explosive in nature; however, it could also open up a very honest space for discussion that can bring new perspectives and understandings.

\section{CONCLUSION}

Feminist researchers have accepted that research is a subjective and messy process and that the complexity of this situation requires honest engagement and public discussion; the interview as objective, written about in a sanitised way, is an idea that has been rejected. Nevertheless, rapport as a critical aspect of this messy and subjective research process has been under-theorised by feminists. This lack of critical discussion minimises the

\section{REFERENCES}

Abell, J., Locke, A., Condor, S., Gibson, S., and Stevenson, C. (2006). Trying similarity, doing difference: the role of interviewer self-disclosure in interview talk with young people. Qual. Res. 6, 221-244. doi:10.1177/1468794106062711 Ahmed, S. (2010). The Promise of Happiness. Durham, NC: Duke University Press. strenuous and complex emotional labour of interviewing. It glosses over the fact that rapport is often accepted as "naturally" occurring-between "gender matched" women-and not interrogated as created, performed, and "unnatural." Certainly reifying gendered binaries through our methodologies simply adds to a highly problematic gendered essentialism in which there is only one way to speak to and access women's experiences "best." By ignoring, minimising, or misunderstanding the complex ethical concerns that exist around rapport we risk reifying the exploitative interview, we are trying to get away from; we need more critical engagement with the wider literature on rapport, and in our own practices in research. If we do not do this, we disengage from our own political ideals and the attempt to create knowledge from as equal a space as possible.

In this article, I have, therefore, argued for two routes forward from this problem. The first is to honestly discuss the rapportbuilding techniques used in interviews and to ensure a smooth discussion and data collection process. Of course, it is always possible that rapport does spontaneously occur, but the lack of reflection on this issue means that feminist researchers do not know the extent of performance of rapport and its impact on the knowledge they/we create and use in the world. This discussion would make much clearer the performative aspects of research, as well as the toll of emotional labour on the researcher. The second route is to forgo rapport, and focus on discussion and debate with participants, rather than creating a space of easy, or cosy, sharing. This option is not straightforward and may not always be practical or possible-but the very fact that there are situations where performance is a better or safer option (for either or both participant and researcher) exposes the work of rapport in managing certain research situations.

There is always an element of exploitation in research. Working towards the ideal of minimising this power imbalance is crucial, but accepting that we engage in a certain level of exploitation of our participants is also key. Researchers could be more honest and move more truly away from objectivity by not managing our emotions as well, not surface (or deep) acting, not worrying about influencing our participants by expressing our thoughts, and in so doing genuinely loosen ourselves from the ties of "objective" research and its standards. Facing the reality of research is something feminists have tried to do for decades, but the conversation around rapport needs to be reenergised with the understanding that, wherever rapport exists, exists a possibility for exploitation and a potential disengagement from the political ideals feminists strive towards in our research practice.

\section{AUTHOR CONTRIBUTIONS}

The author confirms being the sole contributor of this work and approved it for publication.

Berger, R. (2015). Now I see it, now I don't: researcher's position and reflexivity in qualitative research. Qual. Res. 15, 219-234. doi:10.1177/ 1468794112468475

Birch, M., and Miller, T. (2000). Inviting Intimacy: the interview as therapeutic opportunity. Int. J. Soc. Sci. Methodol. 3, 189-202. doi:10.1080/ 13645570050083689 
Birch, M., Miller, T., Mauthner, M., and Jessop, J. (2012). "Introduction to the second edition," in Ethics in Qualitative Research, 2nd Edn, eds T. Miller, M. Birch, M. Mauthner, and J. Jessop (London: SAGE), 1-13.

Boccagni, P. (2011). From rapport to collaboration ... and beyond? Revisiting field relationships in an ethnography of Ecuadorian migrants. Qual. Res. 11, 735-754. doi:10.1177/1468794111415955

Bott, E. (2010). Favourites and others: reflexivity and the shaping of subjectivities and data in qualitative research. Qual. Res. 10, 159-173. doi:10.1177/ 1468794109356736

Brayda, W. C., and Boyce, T. D. (2014). So you really want to interview me? Navigating "sensitive" qualitative research interviewing. Int. J. Qual. Methods 13, 318-334. doi:10.1177/160940691401300115

Collins, P. H. (2009). Black Feminist Thought. London: Routledge.

Collins, P. H., and Bilge, S. (2016). Intersectionality. Cambridge: Polity Press.

Dickson-Swift, V., James, E. L., Kippen, S., and Liamputtong, P. (2007). Doing sensitive research: what challenges do qualitative researchers face? Qual. Res. 7, 327-353. doi:10.1177/1468794107078515

Dunscombe, J., and Jessop, J. (2002). "Doing rapport, and the ethics of 'faking friendship," in Ethics in Qualitative Research, eds T. Miller, M. Birch, M. Mauthner, and J. Jessop (London: SAGE), 108-121.

Evans, L. (2010). Professionalism, professionality and the development of education professionals. Br. J. Educ. Stud. 56, 20-38. doi:10.1111/j.1467-8527.2007.00392.x

Green, G., Barbour, R. S., Barnard, M., and Kitzinger, J. (1993). "Who wears the trousers?" Sexual harassment in research settings. Womens Stud. Int. Forum 16, 627-637. doi:10.1016/S0277-5395(08)80007-6

Gunn, S. (2005). Translating Bourdieu: cultural capital and the English middle class in historical perspective. Br. J. Sociol. 56, 49-64. doi:10.1111/ j.1468-4446.2005.00046.x

Hammersley, M. (2014). On the ethics of interviewing for discourse analysis. Qualitative Research. 14, 529-541. doi:10.1177/1468794113495039

Haraway, D. (1991). Simians, Cyborgs and Women: The Reinvention of Nature. London: Free Association Books.

Harding, S. (1986). The Science Question in Feminism. Ithaca: Cornell University Press.

Hochschild, A. (1983). The Manged Heart: Commercialization of Human Feeling. Berkeley: University of California Press.

Hochschild, A. (2003a). The Manged Heart: Commercialization of Human Feeling. Berkeley: University of California Press.

Hochschild, A. (2003b). The Commercialization of Intimate Life. Berkeley: University of California Press.

Kelly, L., Burton, S., and Regan, L. (1994). "Researching women's lives or studying women's oppression? Reflections on what constitutes feminist research," in Researching Women's Lives from a Feminist Perspective, eds M. Maynard and J. Purvis (London: Taylor and Francis), 27-24.

Korczynski, M. (2003). Communities of coping: collective emotional labour in service work. Organization 10, 55-79. doi:10.1177/1350508403010001479

Lawler, S. (2005). Disgusted subjects: the making of middle-class identities. Sociol. Rev. 53, 429-446. doi:10.1111/j.1467-954X.2005.00560.x

Mann, S. (2005). A health-care model of emotional labour. An evaluation of the literature and development of a model. J. Health Organ. Manag. 19, 304-317. doi:10.1108/14777260510615369

Maynard, M. (1994). "Methods, practice and epistemology," in Researching Women's Lives from a Feminist Perspective, eds M. Maynard and J. Purvis (London: Taylor and Francis), 10-26.
Mitchell, W., and Irvine, A. (2008). I'm okay, you're okay? Reflections on the well-being and ethical requirements of researchers and research participants in conducting qualitative fieldwork interviews. Int. J. Qual. Methods 7, 31-44. doi:10.1177/160940690800700403

Oakley, A. (1981). "Interviewing women: a contradiction in terms?" in Doing Feminist Research, ed. H. Roberts (London: Routledge and Kegan Paul), $30-61$.

Oakley, A. (2015). Interviewing women again: power, time and the gift. Sociology 50, 195-213. doi:10.1177/0038038515580253

Petkov, M. P., and Kaoullas, L. G. (2016). Overcoming respondent resistance at elite interviews using an intermediary. Qual. Res. 16, 411-429. doi:10.1177/ 1468794115589646

Phoenix, A. (1994). "Practising feminist research: the intersection of gender and 'race' in the research process,' in Researching Women's Lives from a Feminist Perspective, eds M. Maynard and J. Purvis (London: Taylor and Francis), 49-71.

Pitts, M. J., and Miller-Day, M. (2007). Upward turning points and positive rapport development across time in researcher-participant relationships. Qual. Res. 7, 177-201. doi:10.1177/1468794107071409

Ramazanoglu, C. (2002). Feminist Methodology: Challenges and Choices. London: SAGE.

Ryan, P. (2006). Researching Irish gay male lives: reflections on disclosure and intellectual autobiography in the production of personal narratives. Qual. Res. 6, 151-168. doi:10.1177/1468794106062707

Skeggs, B. (1997). Formations of Class and Gender. London: SAGE.

Skeggs, B. (2002). "Techniques for telling the reflexive self," in Qualitative Research in Action, ed. T. May (London: SAGE), 349-375.

Soyer, M. (2014). Off the corner and into the kitchen: entering a maledominated research setting as a woman. Qual. Res. 14, 459-472. doi:10.1177/ 1468794113488130

Stanley, L., and Wise, S. (1993). Breaking out again. London: Routledge.

Thwaites, R. (2017). Changing Names and Gendering Identity: Social Organisation in Contemporary Britain. London: Routledge.

Tonnaer, A. (2012). Fifteen minutes in limbo: on the intricacies of rapport in multi-sited fieldwork on tourism. Qual. Res. 12, 565-574. doi:10.1177/ 1468794112450144

Tyler, I. (2008). "Chav Mum Chav Scum" class disgust in contemporary Britain. Fem. Media Stud. 8, 17-34. doi:10.1080/14680770701824779

Yang, F.-H., and Chang, C. C. (2008). Emotional labour, job satisfaction and organizational commitment amongst clinical nurses: a questionnaire survey. Int. J. Nurs. Stud. 45, 879-887. doi:10.1016/j.ijnurstu.2007.02.001

Conflict of Interest Statement: The author declares that the research was conducted in the absence of any commercial or financial relationships that could be construed as a potential conflict of interest.

Copyright $\odot 2017$ Thwaites. This is an open-access article distributed under the terms of the Creative Commons Attribution License (CC BY). The use, distribution or reproduction in other forums is permitted, provided the original author(s) or licensor are credited and that the original publication in this journal is cited, in accordance with accepted academic practice. No use, distribution or reproduction is permitted which does not comply with these terms. 